\title{
Buffering the Suffering of Breast Lymphoscintigraphy
}

\author{
Rex M. Holliday ${ }^{1}$, Manoj K. Jain ${ }^{1}$, Joseph M. Accurso ${ }^{1}$, Akash Sharma ${ }^{1}$, Sara R. Harrison, RT(N) ${ }^{1}$, Debora L. Aloszka, \\ $\mathrm{CNMT}^{1}$, and Andrew W. Bowman ${ }^{2}$ \\ ${ }^{1}$ Division of Nuclear Medicine, Mayo Clinic, Jacksonville, Florida; and ${ }^{2}$ Division of Hospital Radiology, Mayo Clinic, Jacksonville, \\ Florida
}

Breast lymphoscintigraphy with ${ }^{99 m}$ Tc-sulfur colloid is frequently performed before breast-conserving surgery to delineate drainage to a sentinel node. Tracer injection for lymphoscintigraphy can be painful. Our aims were to determine whether administering a solution of buffered lidocaine immediately before lymphoscintigraphy injection could both reduce the patients' pain and increase nuclear medicine technologists' satisfaction with performing the procedure. Methods: A pain scale survey was obtained from patients undergoing breast lymphoscintigraphy with or without buffered lidocaine. Our nuclear medicine technologists were also surveyed for their satisfaction with the procedure, both with and without the addition of buffered lidocaine. Results: The patients' reported pain decreased by $86 \%$ with the addition of buffered lidocaine. Technologist satisfaction with performing the procedure increased by $36 \%$. Conclusion: Lidocaine buffered with sodium bicarbonate injected before lymphoscintigraphy significantly reduces pain experienced by the patient and improves nuclear medicine technologist satisfaction in performing the procedure.

Key Words: breast cancer; sentinel lymph node; lidocaine; anesthesia; lymphoscintigraphy

J Nucl Med Technol 2020; 48:51-53

DOI: $10.2967 / \mathrm{jnmt} .119 .230011$

$\mathbf{F}$ or tumors of appropriate size and stage, breast-conserving surgery offers survival rates equal to modified radical mastectomy (1). Breast lymphoscintigraphy with ${ }^{99 \mathrm{~m}}$ Tc-sulfur colloid is increasingly being performed before breast-conserving surgery to delineate the drainage path to a sentinel node (2).

Tracer injection for lymphoscintigraphy can be painful $(3,4)$; the ${ }^{99 \mathrm{~m}} \mathrm{Tc}$-sulfur colloid solution is acidic, with a $\mathrm{pH}$ generally between 3.5 and 6.0 (5). The pain experienced during lymphoscintigraphy is multifactorial. Aside from the pain felt from the stretching of skin layers during the injection, part of the pain experienced during the procedure has been ascribed to the acidity of the radiotracer solution

\footnotetext{
Received Apr. 18, 2019; revision accepted Jun. 3, 2019.

For correspondence or reprints contact: Andrew W. Bowman, Division of Hospital Radiology, Mayo Clinic, 4500 San Pablo Rd., Jacksonville, FL 32224.

E-mail: bowman.andrew@mayo.edu

Published online Jun. 10, 2019.

COPYRIGHT (c) 2020 by the Society of Nuclear Medicine and Molecular Imaging.
}

(6). Although injection of lidocaine buffered by sodium bicarbonate just before the sulfur colloid administration has demonstrated efficacy in reducing the pain associated with lymphoscintigraphy (4), its use is not uniform in clinical practice. In this study, our goal was to improve the care of our patients with breast cancer by reducing pain during breast lymphoscintigraphy injection. Our primary aim was to determine whether adopting the practice of injecting a solution of buffered lidocaine immediately before the radiotracer injection could significantly reduce the pain experienced during lymphoscintigraphy. Because performing a painful procedure can be a stressor for health-care personnel (7), our secondary aim was to determine whether reducing pain with the addition of the buffered lidocaine injection would also increase procedural satisfaction for the administering technologists.

\section{MATERIALS AND METHODS}

\section{Lymphoscintigraphy Technique}

At our institution, the route of radiotracer administration for breast lymphoscintigraphy is intradermal, with one injection performed lateral and one performed inferior to the areola after the breast has been prepped with povidone-iodine swabs. The dose of sulfur colloid depends on whether the subsequent surgery will be performed the same day or the next. For same-day surgery, 2 injections of filtered sulfur colloid are given, each being $3.7 \mathrm{MBq}$ diluted in normal saline to measure $0.1 \mathrm{~mL}$, for a total of $7.4 \mathrm{MBq}$. For next-day surgery, the injection doses are increased to $11.1 \mathrm{MBq}$ each, similarly diluted in a solution of $0.1 \mathrm{~mL}$, for a total of $22.2 \mathrm{MBq}$. When buffered lidocaine is used, $4.5 \mathrm{~mL}$ of $1 \%$ lidocaine and $0.5 \mathrm{~mL}$ of sodium bicarbonate are drawn into a syringe and mixed, and $0.1 \mathrm{~mL}$ of the buffered lidocaine solution is injected into the skin of the breast at the site of each subsequent lymphoscintigraphy injection. After 10-15 s, the lymphoscintigraphy injection as described above is performed. The breast is then massaged for about $30 \mathrm{~s}$, followed by image acquisition.

\section{Patient Selection and Data Analysis}

Our study was approved by the institutional review board and was compliant with the Health Insurance Portability and Accountability Act. Pre- and postintervention sets of patient data were reviewed. For the preintervention data, 10 patients routinely scheduled for breast lymphoscintigraphy were selected between January 1, 2016, and March 31, 2016, to complete a pain survey. For the pain survey, a pain score was obtained for lymphoscintigraphy using a verbal descriptor scale ranging from 0 to 10 ( 0 being "no pain at all" and 10 being "the worst possible pain imaginable"). We then implemented our intervention of anesthetizing the skin with 
$1 \%$ buffered lidocaine before radiotracer injection. For the postintervention data, 28 patients undergoing lymphoscintigraphy between April 1, 2017, and October 31, 2017, were also asked to complete the same pain survey.

After the intervention, we surveyed 10 nuclear medicine technologists who had administered the sulfur colloid. For this survey, the technologists were asked for their satisfaction with the procedural workflow both before and after the intervention. A similar verbal scale was used, ranging from 0 to 10 ( 0 being "extremely dissatisfied" and 10 being "extremely satisfied").

Differences between the groups in the surveys were assessed with the Student $t$ test. A $P$ value of less than 0.05 was considered significant.

To assess for any impact that addition of buffered lidocaine would have on the diagnostic quality of the lymphoscintigraphy images, 10 examinations performed with and 10 examinations performed without the use of buffered lidocaine were reviewed by 2 board-certified nuclear radiologists who did not know whether buffered lidocaine had been administered. Both radiologists determined whether the studies were of diagnostic quality and whether sentinel lymph nodes could be detected.

\section{RESULTS}

All patients were female. The mean age of the preintervention group was $62.3 \mathrm{y}$, with a median of $64.5 \mathrm{y}$ and a range of $48-78 \mathrm{y}$. The mean age of the postintervention group was $63.0 \mathrm{y}$, with a median of $60.5 \mathrm{y}$ and a range of 39-94 y.

Pain scale score data are summarized in Table 1. Despite the small number of patients surveyed, the decrease in reported pain with the addition of buffered lidocaine was still statistically significant, with a decrease in mean pain scale score by $86 \%(P<0.05)$.

Technologist satisfaction data are summarized in Table 2. Despite the addition of steps to the procedure, including an additional needle stick to administer the buffered lidocaine solution, technologist satisfaction increased significantly, by $36 \%(P<0.05)$.

On masked review of examinations performed with or without the addition of buffered lidocaine, both nuclear radiologists deemed all studies from both groups to be of diagnostic quality, and all studies had a $100 \%$ rate of intraoperative sentinel node detection.

\section{DISCUSSION}

The use of buffered lidocaine for local anesthesia in invasive radiologic procedures, including breast lymphoscintigraphy,

TABLE 1

Pain Scores for Patients Undergoing Lymphoscintigraphy

\begin{tabular}{lcc}
\hline Pain score & $\begin{array}{c}\text { No lidocaine or } \\
\text { sodium bicarbonate } \\
(n=10)\end{array}$ & $\begin{array}{c}\text { Lidocaine and } \\
\text { sodium bicarbonate } \\
(n=28)\end{array}$ \\
\hline Mean & $3.45(\mathrm{SD}, 1.88)$ & $0.50(\mathrm{SD}, 1.32)^{\star}$ \\
Median & 3.25 (range, 1-6) & $0.00($ range, $0-5)$ \\
& & \\
\hline${ }^{*} P=0.001$ & & \\
\hline
\end{tabular}

TABLE 2

Technologist Satisfaction Scores for Lymphoscintigraphy Procedure

\begin{tabular}{lcc}
\hline Satisfaction & $\begin{array}{c}\text { No lidocaine or } \\
\text { sodium } \\
\text { bicarbonate } \\
(n=10)\end{array}$ & $\begin{array}{c}\text { Lidocaine and } \\
\text { sodium } \\
\text { bicarbonate } \\
(n=10)\end{array}$ \\
\hline Mean & $7.3(\mathrm{SD}, 1.6)$ & $9.9(\mathrm{SD}, 0.3)^{\star}$ \\
Median & $8($ range, 5-9) & $10($ range, 9-10) \\
& & \\
${ }^{*} P=0.001$ & & \\
\hline
\end{tabular}

is not new $(4,8,9)$; however, the practice of using local anesthetic immediately before breast lymphoscintigraphy remains highly variable among institutions.

Traditionally, breast lymphoscintigraphy has been performed without local anesthesia for multiple reasons. First, there has been concern that a buffered lidocaine injection before lymphoscintigraphy might diminish visualization of lymph nodes by potentially decreasing lymph node uptake (10). However, similar to reports of other studies $(4,11,12)$, examinations from both groups in our study were deemed to be of diagnostic quality, and all examinations demonstrated $100 \%$ rate of intraoperative sentinel node detection. Second, it had been assumed that any benefit gained from local anesthesia may be offset by the increase in pain from additional needle sticks or pain from the lidocaine itself (4). However, as our pain survey covered the entire lymphoscintigraphy procedure, including the buffered lidocaine injection, our results indicated that the benefits of buffered lidocaine far outweighed either of these putative drawbacks. This advantage was further underscored by the satisfaction survey of our nuclear medicine technologists. Their satisfaction with the procedure substantially increased with the administration of buffered lidocaine, despite the additional injection step and the time (approximately $2-5 \mathrm{~min}$ ) added to the procedure.

Other approaches to reduce the pain of breast lymphoscintigraphy have been proposed previously $(3,13-18)$. A topical anesthetic, such as lidocaine and prilocaine cream, has proven effective in some cases, but a logistic shortcoming is the required 30- to 60-min wait time between cream application and tracer injection to obtain optimum analgesic effect (3). In a study evaluating routine use of topical anesthetic, O'Connor et al. (15) found no statistically significant reduction in pain scores in patients receiving treatment before lymphoscintigraphy. ${ }^{99 \mathrm{~m} T c-t i l m a n o c e p t, ~ a n ~}$ alternative agent (Lymphoseek, sold exclusively through Cardinal Health), is a receptor-targeted lymphatic mapping agent that carries multiple units of mannose, which bind to CD206 receptors in lymph nodes $(13,16-18)$. The $\mathrm{pH}$ of $99 \mathrm{~m}$ Tc-tilmanocept ranges between 6.8 and 7.2, which is much higher than the $3.5-6.0 \mathrm{pH}$ of ${ }^{99 \mathrm{~m}}$ Tc-sulfur colloid. However, ${ }^{99 \mathrm{~m}}$ Tc-tilmanocept is substantially more expensive than sulfur colloid, roughly double the cost of sulfur colloid at our institution (14). 
Limitations of this study include its small sample size. However, the decrease in reported pain with the addition of buffered lidocaine was still statistically significant. Although the study was concluded with a small number of patients, the results caused us to switch our practice to buffered-lidocaine use, and we have anecdotally observed that patient and technologist satisfaction has been maintained. Each group comprised different subjects; therefore, there is a possibility that the pre- and postintervention groups had different pain thresholds. Also, during our postintervention dataset collection, there was a nationwide shortage of sodium bicarbonate, which delayed our completion of the study.

\section{CONCLUSION}

We demonstrated that sodium bicarbonate-buffered lidocaine significantly reduces pain during lymphoscintigraphy, can be administered immediately before the procedure, and has little added cost, no significant increase in procedure time, and no detrimental impact on examination quality. Furthermore, use of the buffered lidocaine makes the procedure less stressful for the technologist, thereby helping maintain or improve the overall examination experience. Accordingly, use of buffered lidocaine before radionuclide injection has become our practice standard, with increased patient and technologist satisfaction.

\section{DISCLOSURE}

No potential conflict of interest relevant to this article was reported. Mayo Clinic does not endorse specific products or services included in this article.

\section{ACKNOWLEDGMENTS}

We acknowledge David J. DiSantis, MD, for manuscript preparation. This work was presented at the 2017 RSNA conference as a digital poster, "Buffering the Suffering of Breast Lymphoscintigraphy," and portions were presented as a poster at the 2018 Florida Radiologic Society Annual Meeting, "The Making of a Quality Improvement Project."

\section{REFERENCES}

1. Fisher B, Anderson S, Bryant J, et al. Twenty-year follow-up of a randomized trial comparing total mastectomy, lumpectomy, and lumpectomy plus irradiation for the treatment of invasive breast cancer. N Engl J Med. 2002;347:1233-1241.

2. Krynyckyi BR, Kim CK, Goyenechea MR, et al. Clinical breast lymphoscintigraphy: optimal techniques for performing studies, image atlas, and analysis of images. Radiographics. 2004;24:121-145.

3. Fetzer S, Holmes S. Relieving the pain of sentinel lymph node biopsy tracer injection. Clin J Oncol Nurs. 2008;12:668-670.

4. Hawkins AS, Yoo DC, Movson JS, et al. Administration of subcutaneous buffered lidocaine prior to breast lymphoscintigraphy reduces pain without decreasing lymph node visualization. J Nucl Med Technol. 2014;42:260-264.

5. Zolle I, ed. Technetium-99m Pharmaceuticals: Preparation and Quality Control in Nuclear Medicine. New York, NY: Springer; 2007.

6. Nieweg OE, Estourgie SH, van Rijk MC, et al. Rationale for superficial injection techniques in lymphatic mapping in breast cancer patients. J Surg Oncol. 2004;87:153-156.

7. French SE, Lenton R, Walters V, et al. An empirical evaluation of an expanded nursing stress scale. J Nurs Meas. 2000;8:161-178.

8. Christoph RA, Buchanan L, Begalla K, et al. Pain reduction in local anesthetic administration through pH buffering. Ann Emerg Med. 1988;17:117-120.

9. Wightman MA, Vaughan RW. Comparison of compounds used for intradermal anesthesia. Anesthesiology. 1976;45:687-689.

10. Arciero CA, Henry LR, Howard RS, et al. Technical effects of adding $1 \%$ lidocaine to technetium sulfur colloid for sentinel lymphatic mapping in early breast cancer: analysis of data from a double-blind randomized controlled trial. Ann Surg Oncol. 2013;20:2548-2555.

11. Stearns V, Blackford A, Kessler J, et al. Diagnostic accuracy of sentinel node identification is maintained with the addition of local lidocaine and subareolar radioactive colloid injection. Breast Cancer Res Treat. 2015;150:589-595.

12. Stojadinovic A, Peoples GE, Jurgens JS, et al. Standard versus $\mathrm{pH}$-adjusted and lidocaine supplemented radiocolloid for patients undergoing sentinel-lymph-node mapping and biopsy for early breast cancer (PASSION-P trial): a double-blind, randomised controlled trial. Lancet Oncol. 2009;10:849-854.

13. Lymphoseek injection [prescribing information]. Dublin, OH: Cardinal Health; 2017.

14. Lymphoseek (technetium Tc 99m tilmanocept) injection. Cardinal Health website. https://www.cardinalhealth.com/en/product-solutions/pharmaceutical-products/ nuclear-medicine/radiopharmaceuticals/spect/lymphoseek.html. Accessed March 22, 2019.

15. O'Connor JM, Helmer SD, Osland JS, et al. Do topical anesthetics reduce periareolar injectional pain before sentinel lymph node biopsy? Am J Surg. 2011;202: 707-711.

16. Sondak VK, King DW, Zager JS, et al. Combined analysis of phase III trials evaluating $\left[{ }^{99 \mathrm{~m}} \mathrm{Tc}\right]$ tilmanocept and vital blue dye for identification of sentinel lymph nodes in clinically node-negative cutaneous melanoma. Ann Surg Oncol. 2013;20:680-688.

17. Wallace AM, Han LK, Povoski SP, et al. Comparative evaluation of [ $\left.{ }^{99 \mathrm{~m}} \mathrm{Tc}\right]$ tilmanocept for sentinel lymph node mapping in breast cancer patients: results of two phase 3 trials. Ann Surg Oncol. 2013;20:2590-2599.

18. Wallace AM, Hoh CK, Ellner SJ, et al. Lymphoseek: a molecular imaging agent for melanoma sentinel lymph node mapping. Ann Surg Oncol. 2007;14:913-921. 